\title{
CUSTO DE PRODUÇÃO E SUSTENTABILIDADE DO LEITE
}

\author{
Maycon Amim Vueira ${ }^{1}$, Flávio Alberto Oliva ${ }^{1}$, Douglas Fernandes ${ }^{2}$ \\ ${ }^{1}$ Universidade do Oeste Paulista - UNOESTE, Presidente Prudente - SP. ${ }^{2}$ Faculdade de Tecnologia de Presidente \\ Prudente - FATEC, Presidente Prudente - SP
}

\section{RESUMO}

As alterações econômicas sucedidas desde o começo da década de 90 vêm exigindo aceleradas adequações estratégicas e estruturais na cadeia produtiva do leite. A desregulamentação do comércio leiteiro, acompanhadas de uma maior abertura comercial da economia brasileira resultaram em uma maior concorrência em termos de qualidade e escala de produção. Nesse contexto, o presente trabalho tem como objetivo apresentar dados referentes ao custo de produção e rentabilidade por meio de estudo de caso em uma propriedade, analisando seus números e discutindo possíveis alternativas para reversão de resultados negativos. Logo, a metodologia recai sobre o entendimento e aplicação dos conceitos e técnicas de mensuração de custos no processo gerencial e custos como ferramenta de controle. Análise da rentabilidade, cálculo de custos operacionais da unidade de produção em estudo (insumos, mão-de-obra, máquinas e implementos agrícolas, custos administrativos e custos de oportunidades). Levantamento de dados, tabulação e montagem de relatórios gerenciais para a tomada de decisão e controle. No presente trabalho, é possível notar que a Receita Liquida (déficit e superávit) esta relacionada inversamente proporcional ao Custo Total (CT), além de outros índices que permite o produtor identificar os pontos fracos e fortes de sua produção.

Palavras-chave: Despesas, Receitas, Custo.

\section{COST OF MILK PRODUCTION AND SUSTAINABILITY}

\begin{abstract}
Successful economic changes since the beginning of the Decade of 90 come demanding accelerated strategic and structural adjustments in the production chain of milk. Deregulation of the dairy trade, accompanied by a greater commercial opening of the Brazilian economy have resulted in greater competition in terms of quality and scale of production. In this context, the present study aims to present data on cost of production and profitability through case study on a property, analyzing their numbers and discussing possible alternatives for reversal of negative results. Soon, the methodology rests on the understanding and application of concepts and techniques of measuring costs in the management process and costs as a tool of control. Profitability analysis, calculation of operating costs of the production unit under study (inputs, labor, machinery and agricultural implements, administrative costs and costs of opportunities). Data collection, tabulation and Assembly of management reports for decision making and control. In the present work, it is possible to notice that the Revenues (deficit and surplus) this related inversely proportional to the Total cost (TC), in addition to other indexes that allows producers to identify the strengths and weaknesses of their production.
\end{abstract}

Keywords: Expenditure, Revenue, Cost. 


\section{INTRODUÇÃO}

Segundo Reis et. al. (2002), as alterações econômicas sucedidas desde o começo da década de 90 vêm exigindo aceleradas adaptações estratégicas e estruturais no setor agroindustrial do leite. A desregulamentação do comércio leiteiro e, em seguida, a abertura comercial da economia brasileira resultaram em um comércio competidor em termos de qualidade, produção e escala de produção.

Conforme a FAO (2009), a produção brasileira é de 1.235 litros/vaca/ano, 7,4 vezes mais baixo que a produção mundial. A produção norte-americana é de 9.118 litros/vaca/ano, o que demonstra a baixa produtividade brasileira. O Brasil tem o segundo maior rebanho para produção leite do mundo, ficando na retaguarda apenas da Índia, ocupando também a quinta posição entre os principais países que produzem leite bovino no mundo, com uma produção de 29,1 mil toneladas. Na primeira posição estão os Estados Unidos com 85,8 mil ton. seguidos pela Índia com 45,1 mil ton., China com 35,5 mil ton. e Federação Russa com 32,3 mil ton.

Sendo assim, Lopes et. al. (2004), afirma que diferentes alterações, dentre outros acontecimentos, têm colaborado para que os produtores de leite reflitam sobre a precisão de conduzirem adequadamente a atividade, tornando-se mais competentes e, consequentemente, competitivos. Frente a esta realidade, ter domínio acertado e, sobretudo um sistema de custo de produção de leite que produza dados para a tomada de decisões objetivas, é fundamental para o sucesso do empreendimento.

A necessidade de avaliar economicamente a atividade leiteira é crucial, com ela, o produtor identifica e aproveita de maneira inteligente e eficiente os fatores de produção. Localizar pontos críticos para concentrar empenhos gerenciais e/ou tecnológicos objetivando o sucesso da atividade por meio da maximização dos lucros (LOPES; CARVALHO, 2000).

\section{OBJETIVO}

Apresentar a apuração de custos de produção de leite de uma propriedade experimental subsidiando indicadores necessários para tomada de decisão gerencial e estratégica.

\section{MATERIAL E MÉTODOS}

A metodologia recai sobre o entendimento e aplicação dos conceitos e técnicas de mensuração de custos no processo gerencial e custos como ferramenta de controle. Análise da rentabilidade, cálculo dos custos operacionais (insumos, mão-de-obra, máquinas e implementos 
agrícolas e custos administrativos). Levantamento de dados, tabulação e montagem de relatórios gerenciais para a tomada de decisão e controle obtidos de uma propriedade experimental.

\section{RESULTADOS E DISCUSSÃO}

Conforme tabelas 1, 2 e gráfico 1, a propriedade em questão, no primeiro semestre de 2012 apresentou, de janeiro a maio, índices de lucratividade negativos. Apenas no último mês do semestre o resultado foi positivo, porém, insuficiente para recuperar os resultados dos meses anteriores.

No segundo semestre, tabela 2, embora os meses de agosto e setembro tenham produzido lucratividade positiva, os demais meses produziram resultados negativos totalizando, ao final do semestre a lucratividade média negativa de 13,63\%. No ano de 2012 a lucratividade média foi de $60,26 \%$.

Tabela 1. Total de despesas, receita líquida e lucratividade no primeiro semestre de 2012.

\begin{tabular}{|c|c|c|c|c|c|c|}
\hline & JAN & FEV & MAR & ABR & MAI & JUN \\
\hline & $\mathbf{R} \$$ & $\mathbf{R} \mathbf{S}$ & $\mathbf{R} \$$ & $\mathbf{R} \mathbf{S}$ & $\mathbf{R} \$$ & $\mathbf{R} \$$ \\
\hline Receita Bruta & $3.960,00$ & $4.469,40$ & $3.864,60$ & $3.297,60$ & $3.297,60$ & $4.443,30$ \\
\hline \multicolumn{7}{|l|}{ Despesas } \\
\hline \multicolumn{7}{|l|}{ Folha de } \\
\hline Pagamento & $1.683,43$ & $3.682,24$ & $2.895,64$ & $2.895,64$ & $2.895,64$ & $2.895,65$ \\
\hline \multicolumn{7}{|l|}{ Medicam } \\
\hline alimentação & $3.514,13$ & $3.996,34$ & $3.157,46$ & 136,64 & $8.370,48$ & 249,58 \\
\hline Almoxarifado & 0,29 & $1.825,10$ & 366,35 & $2.293,55$ & $1.416,78$ & 16,66 \\
\hline Energia & 232,42 & 231,20 & 292,29 & 240,67 & 262,92 & 249,25 \\
\hline Manutenções & - & 172,20 & 123,03 & 158,96 & 175,12 & - \\
\hline Depreciação & 243,06 & 243,06 & 223,61 & 223,61 & 223,61 & 223,61 \\
\hline Outras despesas & 150,00 & 115,42 & 114,18 & - & 397,34 & - \\
\hline \multicolumn{7}{|l|}{ Total das } \\
\hline Despesas & $5.823,33$ & $10.265,56$ & $7.172,56$ & $5.949,07$ & $13.741,89$ & $3.634,75$ \\
\hline Receita Liquida & $-1.863,33$ & $-5.796,16$ & $-3.307,96$ & $-2.651,47$ & $-10.444,29$ & 808,55 \\
\hline
\end{tabular}


Tabela 2. Total de despesas, receita líquida e lucratividade no segundo semestre de 2012.

\begin{tabular}{|c|c|c|c|c|c|c|}
\hline & JUL & AGO & SET & OUT & NOV & DEZ \\
\hline Receita Bruta & $\begin{array}{r}\mathrm{R} \$ \\
5.877,00\end{array}$ & $\begin{array}{r}R \$ \\
6.740,10\end{array}$ & $\begin{array}{r}\mathrm{R} \$ \\
7.866,00\end{array}$ & $\begin{array}{r}R \$ \\
8.245,80\end{array}$ & $\begin{array}{r}\mathrm{R} \$ \\
7.200,00\end{array}$ & $4.320,00$ \\
\hline \multicolumn{7}{|l|}{ Despesas } \\
\hline Folha de Pagamento & $2.895,64$ & $2.941,08$ & $2.941,08$ & $2.941,08$ & $2.941,08$ & $2.600,06$ \\
\hline $\begin{array}{l}\text { Medicam e } \\
\text { alimentação }\end{array}$ & $2.601,08$ & $1.693,50$ & $1.502,27$ & $3.713,44$ & $4.991,26$ & $3.789,18$ \\
\hline Almoxarifado & 89,19 & 130,19 & 82,56 & 121,39 & 510,49 & - \\
\hline Energia & 254,86 & 313,51 & 800,67 & 842,07 & 877,79 & 769,74 \\
\hline Manutenções & 9,94 & - & 151,42 & 180,22 & 212,85 & 200,63 \\
\hline Depreciação & 252,78 & 252,78 & 320,83 & 311,11 & 320,83 & 252,78 \\
\hline Outras despesas & 60,00 & 283,48 & 138,70 & 393,18 & 140,58 & - \\
\hline Total das Despesas & $6.163,49$ & $5.614,54$ & $5.937,53$ & $8.502,49$ & $9.994,88$ & $7.612,39$ \\
\hline Receita Liquida & $-286,49$ & $1.125,56$ & $1.928,47$ & $-256,69$ & $-2.794,88$ & $-3.292,39$ \\
\hline
\end{tabular}

Gráfico 1. Avaliação dos índices de Receita Bruta, Custo Total e Receita Liquida em 2012.

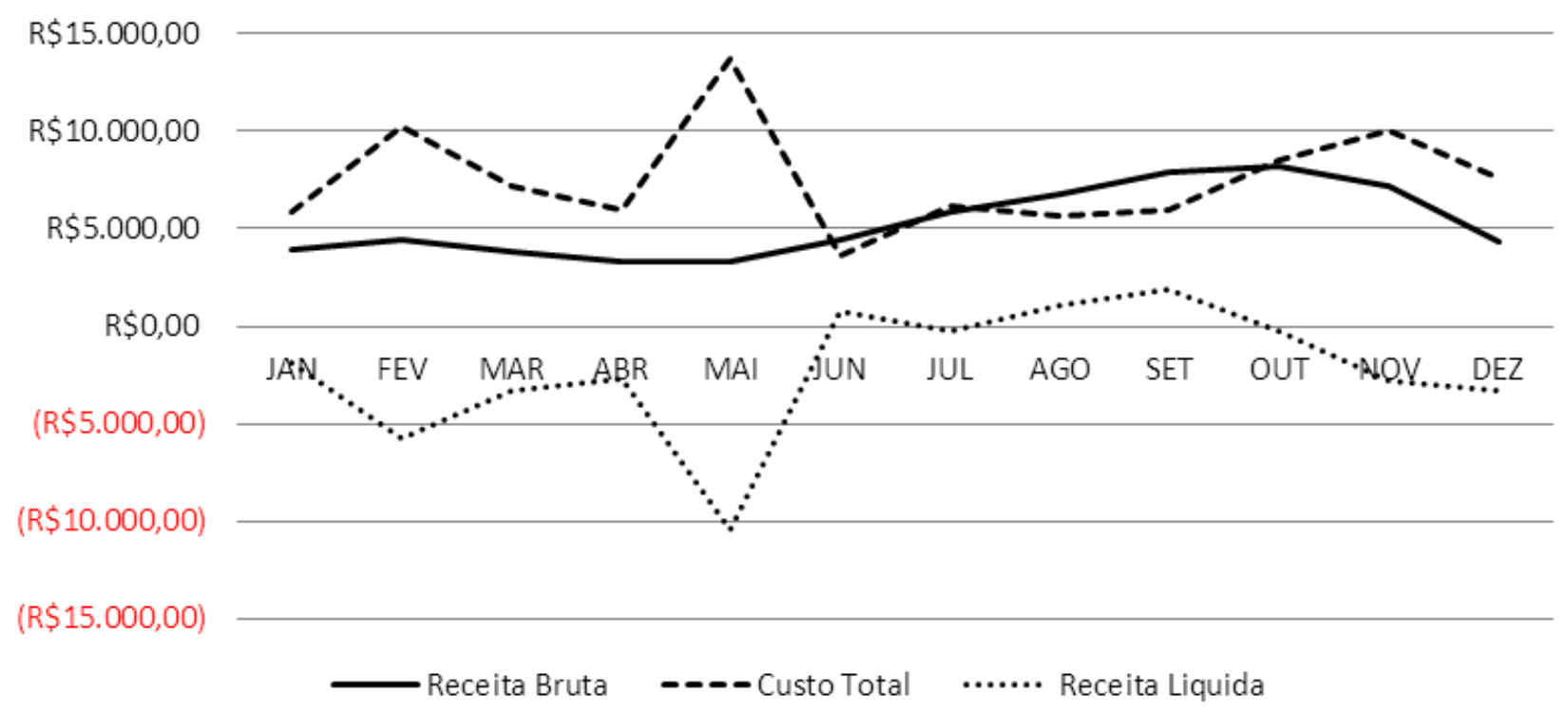

Nas tabelas 3, 4 e gráfico 2, foram retratados os resultados da atividade leiteira para o ano de 2013. No primeiro semestre, tabela 3, o índice de lucratividade apresentou-se negativo para todos os meses, totalizando no semestre a média de lucratividade de $-63,30 \%$.

No segundo semestre, os meses de agosto, outubro e dezembro apresentaram desempenho de lucratividade positivo, porém, a média do semestre foi negativa em $47,75 \%$. 
Tabela 3. Total de despesas, receita líquida e lucratividade no primeiro semestre de 2013.

\begin{tabular}{|c|c|c|c|c|c|c|}
\hline & JAN & FEV & MAR & ABR & MAI & JUN \\
\hline & $\mathbf{R} \$$ & $\mathbf{R} \$$ & $\mathbf{R} \$$ & $\mathbf{R} \$$ & $\mathbf{R} \$$ & $\mathbf{R} \$$ \\
\hline Receita Bruta & $6.371,10$ & $5.677,20$ & $5.854,50$ & $5.143,50$ & $4.433,40$ & $3.453,30$ \\
\hline \multicolumn{7}{|l|}{ Despesas } \\
\hline Folha de Pagamento & $2.763,53$ & $3.546,79$ & $3.235,17$ & $3.488,93$ & $3.371,51$ & $3.235,17$ \\
\hline Medicamento e alimentação & $4.445,39$ & $2.817,39$ & $5.343,30$ & $1.177,44$ & $4.723,79$ & $1.069,16$ \\
\hline Almoxarifado & $1.371,46$ & 187,47 & $1.146,88$ & 102,93 & 193,44 & 12,94 \\
\hline Energia & 700,01 & 524,94 & 480,54 & 506,61 & 573,84 & 625,55 \\
\hline Manutenções & 918,88 & 379,40 & 578,97 & - & 79,18 & \\
\hline Depreciação & 281,94 & 252,78 & 252,78 & 252,78 & 223,61 & 175,00 \\
\hline Outras despesas & 279,74 & 228,66 & 136,98 & 140,58 & 470,08 & 153,90 \\
\hline Total das Despesas & $10.760,95$ & $7.937,43$ & $11.174,62$ & $5.669,27$ & $9.635,45$ & $5.271,72$ \\
\hline Receita Liquida & $-4.389,85$ & $-2.260,23$ & $-5.320,12$ & $-525,77$ & $-5.202,05$ & $-1.818,42$ \\
\hline
\end{tabular}

Tabela 4. Total de despesas, receita líquida e lucratividade no segundo semestre de 2013.

\begin{tabular}{|c|c|c|c|c|c|c|}
\hline & JUL & AGO & SET & OUT & NOV & DEZ \\
\hline & $\mathbf{R} \mathbf{S}$ & $\mathbf{R} \$$ & $\mathbf{R} \mathbf{S}$ & $\mathbf{R} \mathbf{S}$ & $\mathbf{R} \$$ & $\mathbf{R} \$$ \\
\hline Receita Bruta & $4.923,00$ & $5.224,50$ & $5.432,40$ & $5.490,00$ & $6.390,00$ & $6.390,00$ \\
\hline \multicolumn{7}{|l|}{ Despesas } \\
\hline Folha de Pagamento & $3.235,17$ & $3.235,17$ & $3.386,27$ & $3.386,27$ & $3.386,27$ & $3.090,54$ \\
\hline Medicamento e alimentação & $6.022,64$ & 429,66 & $4.914,93$ & 327,46 & $7.626,69$ & 235,49 \\
\hline Almoxarifado & 301,10 & 85,16 & 967,39 & 292,63 & $1.545,42$ & 515,99 \\
\hline Energia & 597,11 & 584,95 & 667,69 & 644,38 & 779,55 & 827,29 \\
\hline Manutenções & - & 23,99 & 2,90 & - & - & 41,64 \\
\hline Depreciação & 252,78 & 243,06 & 272,22 & 272,22 & 272,22 & 272,22 \\
\hline Outras despesas & 214,70 & 151,44 & 153,22 & 194,16 & 152,50 & $\mathrm{R} 152,18$ \\
\hline Total das Despesas & $10.623,50$ & $4.753,43$ & $10.364,62$ & $5.117,12$ & $13.762,65$ & $5.135,35$ \\
\hline Receita Liquida & $-5.700,50$ & 471,07 & $-4.932,22$ & 372,88 & $-7.372,65$ & $1.254,65$ \\
\hline
\end{tabular}

Gráfico 2. Avaliação dos índices de Receita Bruta, Custo Total e Receita Liquida em 2013.

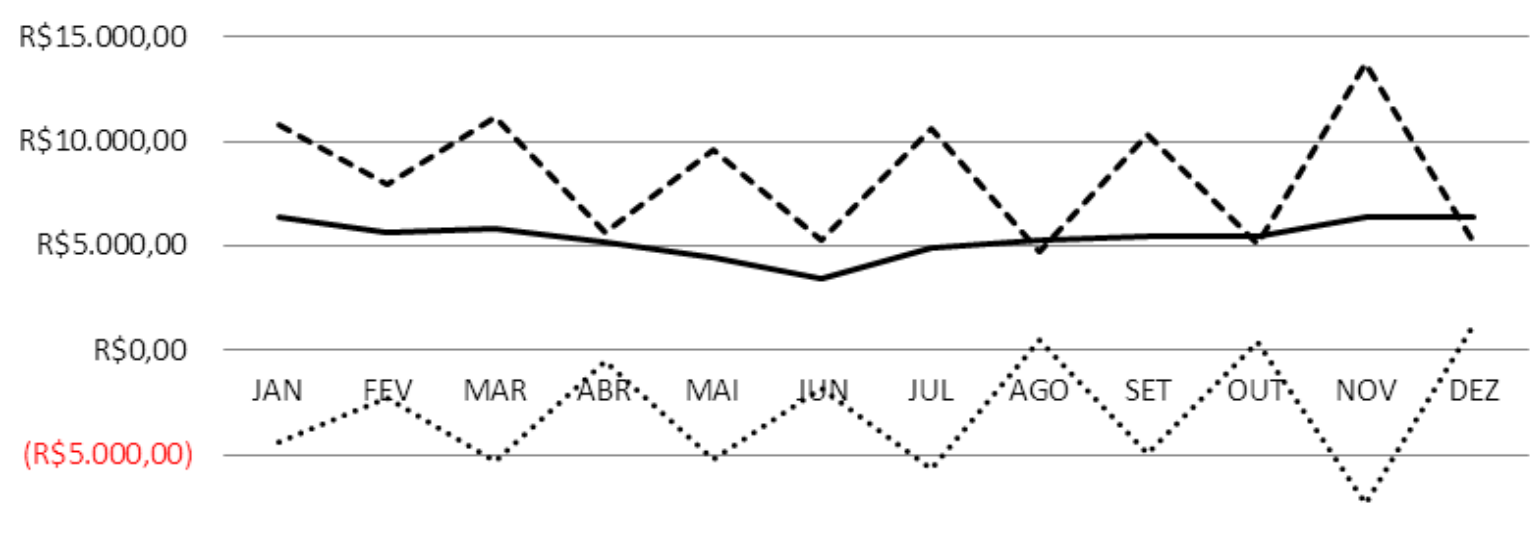

$(\mathrm{R} \$ 10.000,00)$

— Receita Bruta ----Custo Total $\quad$....... Receita Liquida 
Gráfico 3. Custo de Produção 2012.

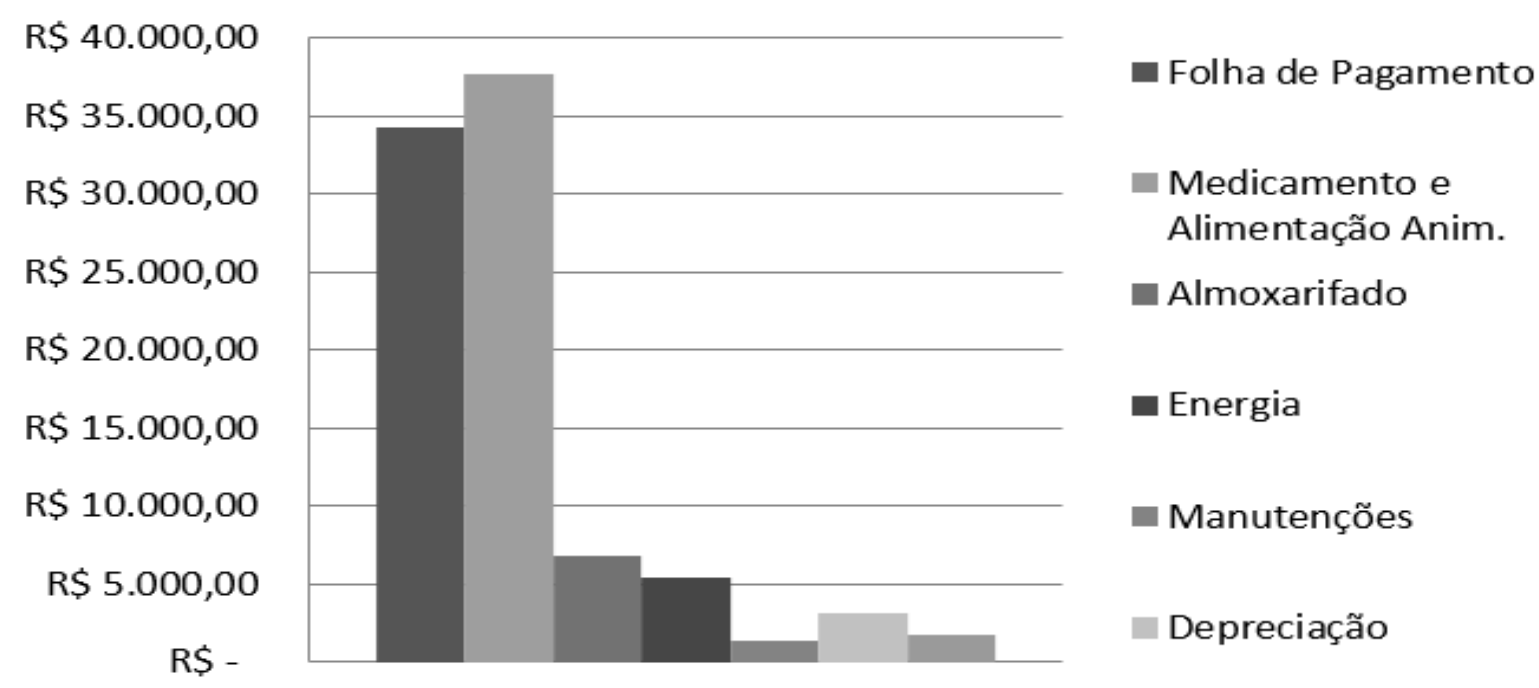

No gráfico 3, Custo de Produção do ano de 2012, observa-se que as despesas com folha de pagamento, medicamentos e alimentação animal são os principais dispêndios da atividade, totalizando $79,55 \%$ dos custos e despesas totais.

Gráfico 4. Custo de Produção 2013.

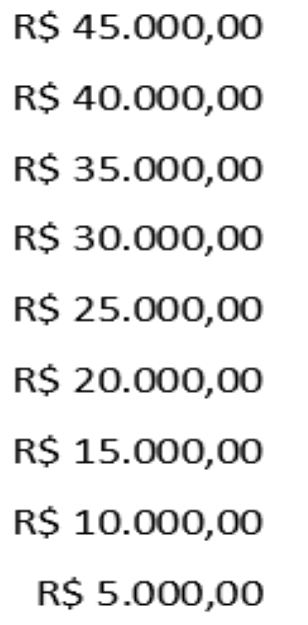

RS -

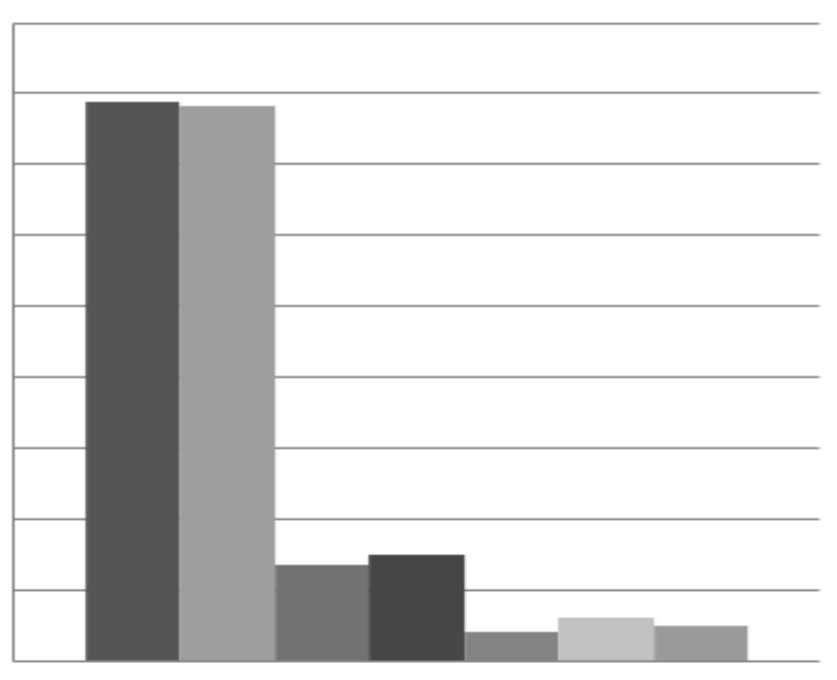

Folha de Pagamento

Medicamento e Alimentação Anim.

- Almoxarifado

- Energia

Manutenções

Depreciação

A análise do Custo de Produção de 2013, gráfico 4, revela situação similar ao ano anterior. As despesas com folha de pagamento, medicamentos e alimentação animal totalizaram $78,33 \%$ dos custos e despesas totais. Embora apresentando uma queda de 1,22\% em relação ao ano anterior, a lucratividade foi de $-55,53 \%$, sendo que a lucratividade de 2012 foi de $-60,26 \%$. A diminuição dos custos e despesas totais em 1,22\% provocou melhoria na lucratividade em 4,73\%. 
Gráfico 5. Produtividade do rebanho em 2012

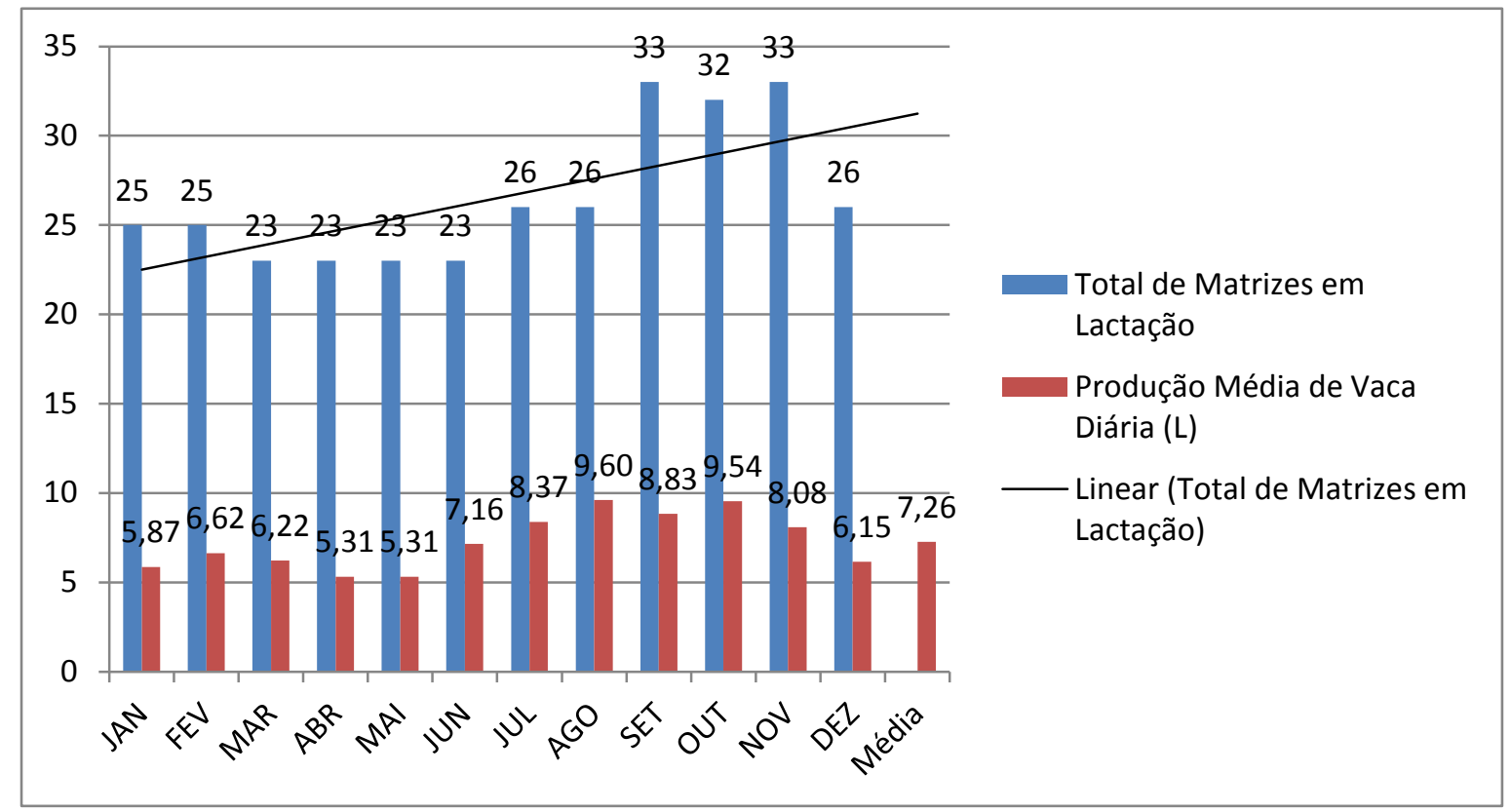

Gráfico 6. Produtividade do rebanho em 2013

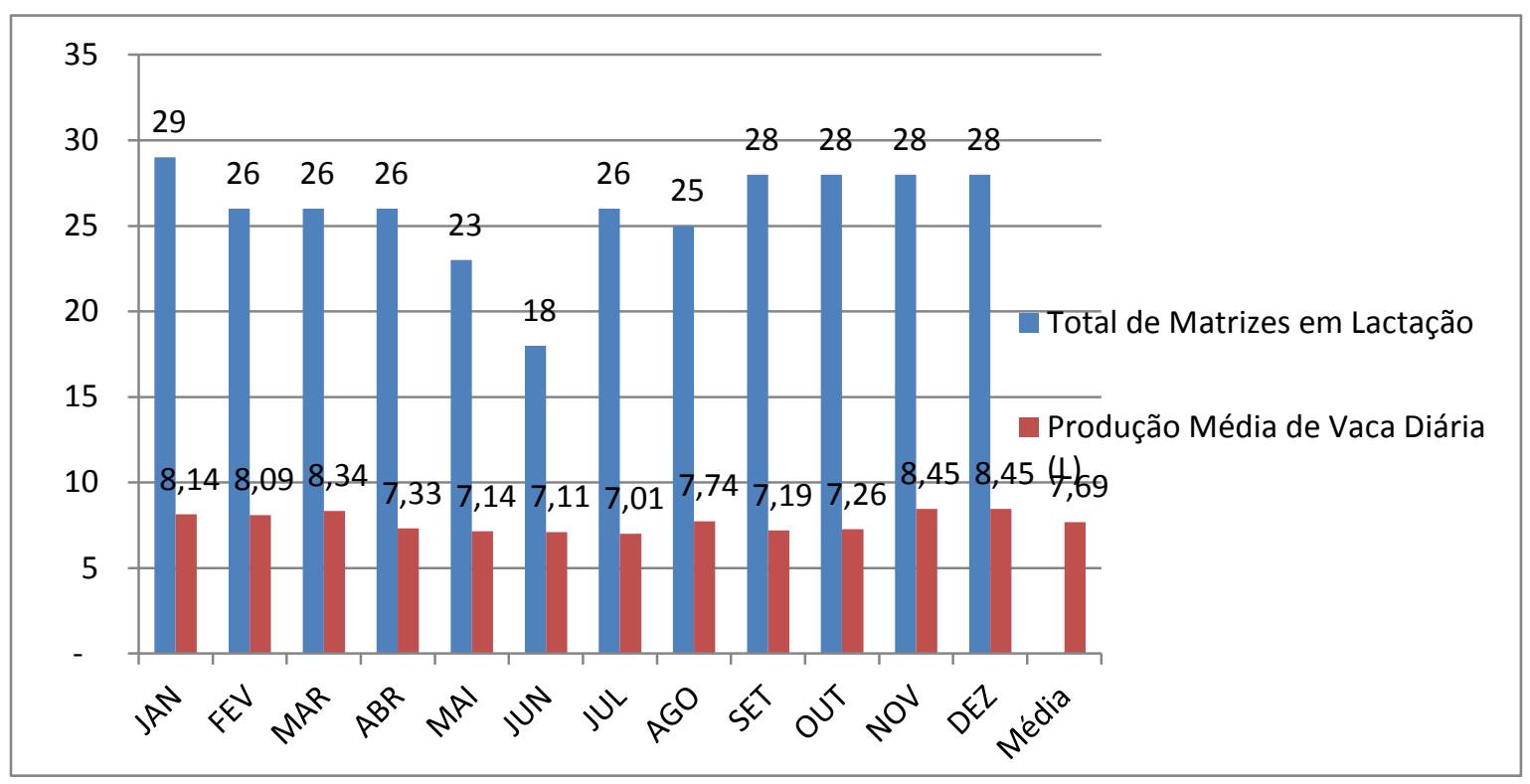

\section{CONSIDERAÇÕES FINAIS}

A realidade da unidade de produção de leite analisada não diverge da maioria das propriedades produtoras de leite do Brasil. A produtividade por vaca é insuficiente para a cobertura de custos e despesas contribuindo, dessa maneira, para os resultados negativos apurados.

Apesar do aumento de produtividade por animal, constatado de 2012 para 2013, o mesmo foi insuficiente para compensar o aumento de custos no mesmo período. Quando comparado a relação custo total médio mensal com a receita média mensal, observa-se uma piora no 
desempenho de 2012 para 2013, visto que no primeiro período o custo total médio mensal foi de $\mathrm{R} \$ 7.534,37$ a receita média mensal de $\mathrm{R} \$ 5.298,45$, apresentado um índice de 1,42 para o período. Em 2013, a mesma relação é de 1,55 (custo total médio mensal de $R \$$ 8.350,51 e receita média mensal de $\mathrm{R} \$ 5.398,58)$.

Os custos totais, quando de uma análise estritamente econômica, na média mensal de 2013, verifica-se aumento de $10,83 \%$ no custo total médio mensal (de $\mathrm{R} \$ 7.515,46$ para $\mathrm{R} \$$ $8.350,51)$.

Como alternativa para equilibrar a relação custo e receita, a propriedade deve associar técnicas de manejo do rebanho com controle de custos.

Observa-se, pelos resultados apresentados, e tratando-se de uma propriedade experimental, vocacionada para o ensino das ciências agrárias, as práticas gerenciais, neste caso, não estão sendo aplicadas. No presente estudo buscou-se evidenciar que as metodologias gerenciais são fundamentais para a melhoria do manejo do rebanho, objetivando a eficiência, a eficácia e o lucro. A propriedade deve implementar conjuntamente práticas de manejo e de gerenciamento da atividade.

\section{REFERÊNCIAS}

FAO - Food Agriculture Organization. Disponível em: <http://faostat.fao.org/default.jsp>. Acesso em 05 de abril de 2014.

HELFERT, Erich A. Técnicas de análise financeira: um guia prático para medir o desempenho dos negócios. 9.ed. Porto Alegre: Bookman, 2000.

LOPES, M. A.; LIMA, A. L. R.; CARVALhO, F. de M.; REIS, R. P.; SANTOS, I. C.; SARAIVA, F. H. Controle gerencial e estudo da rentabilidade de sistemas de produção de leite na região de Lavras (MG), Ciência e Agrotecnologia, v. 28, n. 4, p. 883-892, 2004. http://dx.doi.org/10.1590/S1413-70542004000400022

LOPES, M. A.; CARVALHO, F. de M. Custo de produção do leite. Lavras: UFLA, 2000. 42 p. (Boletim Agropecuário, 32).

MARTINS, Eliseu. Contabilidade de custos. 6.ed. São Paulo: Atlas, 1998.

REIS, R. P. Fundamentos de economia aplicada. Lavras: UFLA/FAEPE, 2002. 84 p. 